\title{
Clinical potential of gene mutations in lung cancer
}

\author{
Miranda B. Carper ${ }^{1}$ and Pier Paolo Claudio $2,3^{*}$
}

\begin{abstract}
Lung cancer is the most common cancer type worldwide and the leading cause of cancer related deaths in the United States. The majority of newly diagnosed patients present with late stage metastatic lung cancer that is inoperable and resistant to therapies. High-throughput genomic technologies have made the identification of genetic mutations that promote lung cancer progression possible. Identification of the mutations that drive lung cancer provided new targets for non-small cell lung cancer (NSCLC) treatment and led to the development of targeted therapies such as tyrosine kinase inhibitors that can be used to combat the molecular changes that promote cancer progression. Development of targeted therapies is not the only clinical benefit of gene analysis studies. Biomarkers identified from gene analysis can be used for early lung cancer detection, determine patient's prognosis and response to therapy, and monitor disease progression. Biomarkers can be used to identify the NSCLC patient population that would most benefit from treatment (targeted therapies or chemotherapies), providing clinicians tools that can be used to develop a personalized treatment plan. This review explores the clinical potential of NSCLC genetic studies on diagnosing and treating NSCLC.
\end{abstract}

Keywords: NSCLC, Mutations, Targeted therapy, Personalized therapy, Biomarkers, Bench-to-bedside

\section{Introduction}

Lung cancer is the leading cause of cancer related deaths in both men $(28 \%)$ and women $(27 \%)$ in the United States [1]. In 2015, the American Cancer Society estimates 221,200 patients will be diagnosed with lung cancer and 158,040 deaths will occur due to this disease [1]. The majority of lung cancers are diagnosed at a late stage resulting in a 5 year survival rate $(17 \%)$ that is lower than breast (89\%), prostate (99\%), and colon carcinomas (65\%) [1]. The high death rates associated with lung cancer highlight the need for improved diagnosis and treatment procedures. Lung cancer is broken down into two main categories, non-small-cell lung cancer (NSCLC) and small-cell lung cancer (SCLC) based on cell morphology. NSCLC accounts for $85 \%$ of all lung cancers and is subcategorized into pulmonary adenocarcinomas, squamous cell carcinomas, and large cell carcinomas

\footnotetext{
*Correspondence: pclaudio@olemiss.edu

${ }^{2}$ Department of Radiation Oncology, The University of Mississippi Medical Center Cancer Institute, 350 W Woodrow Wilson Ave, Jackson, MS 39213, USA

Full list of author information is available at the end of the article
}

(LCC) [2]. Forty, twenty-five, and ten percent of all lung cancers are diagnosed as adenocarcinomas, squamous cell carcinomas, and large cell carcinomas, respectively [2].

The first step to developing new treatments for any disease is to understand the molecular biology driving its progression. Development and implementation of high-throughput genomic technologies such as next generation sequencing (NGS) enable genotyping of tumors at a lower cost and quicker turn around than was previously possible $[3,4]$. NGS and other nucleic acid sequencing technologies (reviewed in $[3,4]$ ) have identified genetic mutations that drive lung cancer progression often referred to as "oncogenic drivers". Discovery of lung cancer drivers has led to the development of therapies that target cancer cells and inhibit the pathways that promote lung cancer growth and progression. The use of targeted therapies have led to an increase in survival of lung cancer patients with certain genetic alterations such as epidermal growth factor receptor (EGFR) activating mutations and anaplastic lymphoma kinase (ALK) rearrangements [5-7]. Gefitinib, a small molecule

\section{量 Springer}

(c) 2015 Carper and Claudio. This article is distributed under the terms of the Creative Commons Attribution 4.0 International License (http://creativecommons.org/licenses/by/4.0/), which permits unrestricted use, distribution, and reproduction in any medium, provided you give appropriate credit to the original author(s) and the source, provide a link to the Creative Commons license, and indicate if changes were made. 
inhibitor for the EGFR receptor was approved for use to treat NSCLC in May of 2003 [6]. Gefitinib was one of the first tyrosine kinase inhibitors and targeted therapies approved for NSCLC with aberrant activation of the EGFR pathway [8]. Gefitinib is an example of how discoveries made by basic science researchers on molecular changes in cancers can translate to provide therapies that can be utilized in the clinic.

However, the clinical significance of studying lung cancer mutations goes beyond drug development. Investigation and characterization of NSCLC mutations can also be used to identify biomarkers that can be used for early diagnosis and predicting patients' prognosis and response to treatment that can be used to determine a personalized therapeutic regimen. This review will explore the clinical benefits of genetic mutation investigations for patients with NSCLC with an emphasis on use of gene biomarkers for diagnosis and treatment.

\section{Review}

\section{Lung cancer mutations and targeted therapy} Mutations in NSCLC

NSCLC is a heterogeneous disease marked with a high rate of somatic mutations. Genetic analyses of the NSCLC subtypes lung adenocarcinomas and squamous cell carcinomas found a higher rate of mutations in these cancers than acute myelogenous leukemia, glioblastoma multiforme, and cancers of the breast, ovaries, and colon $[9,10]$. The Cancer Genome Atlas (TCGA) research network and other groups, have identified several genes altered (by mutations, amplification, or rearrangements) in adenocarcinomas such as: EGFR, EML4-ALK (Echinoderm microtubule associated protein-like protein 4 fused with Anaplastic Lymphoma Kinase), KRAS (Kirsten rat sarcoma viral oncogene homolog), MET (mesenchymal-epithelial transition factor), ROS1 (c-ros oncogene 1), RET (rearranged during transfection), BRAF ( $v$-Raf murine sarcoma viral oncogene homolog B1), and TP53 (tumor suppressor protein 53) and in squamous cell carcinomas: FGFR1 (fibroblast growth factor receptor 1), PIK3CA (phosphoinositide-3-kinase catalytic subunit alpha isoform), DDR2 (discoidin domain receptor 2), MET, SOX2 (SRY related HMG box gene 2), PTEN (phosphatase and tensin homolog), CDKN2A (TP53 and cyclin-dependent kinase inhibitor 2A) highlighted in Table $1[9,10]$.

A large majority of altered genes code for proteins that are involved in receptor tyrosine kinase (RTK) signaling, leading to the promotion of NSCLC cell proliferation, survival, migration, and invasion (Table 1) [9-13]. Several mutations or amplifications occur in genes for the RTKs: EGFR, ALK, MET, ROS1, RET, FGFR1 and DDR2 or in genes that help facilitate RTK downstream signaling events such as: KRAS, BRAF, and PIK3CA (phosphoinositide-3-kinase (PI3K) family member) in NSCLC [913]. PTEN mutations and/or deletions occur in 15-20\% of squamous cell carcinomas and leads to aberrant activation of the PI3K pathway (Table 1). Although genetic alterations occur in both adenocarcinomas and squamous cell carcinomas effecting RTK signaling, these NSCLC sub-types have different dominant mutations, amplifications, or rearrangements (Table 1). For example, EGFR and KRAS are two of the most commonly mutated genes in lung adenocarcinomas; however they are rarely mutated in lung squamous cell carcinomas (Table 1) $[9,10]$.

The advent of technology and assays that allow the sequencing and analysis of the genome has resulted in an influx of information regarding NSCLC and increased the number of possible therapeutic targets. The NSCL genetic alterations represented in Table 1 barely scratches the surface in regards to the many different genomic abnormalities that have been identified. The question remains which of the identified mutations constitute good targets for therapeutic intervention in NSCLC? However, these genetic alterations are of interest to researchers for several reasons including; the rate of occurrence in NSCLC and/or the ability of these changes in the genome to drive oncogenesis. The rate of occurrence in NSCLC and the ability of these changes in the genome to drive oncogenesis are two criteria used to determine pharmaceutical targets [14]. In the next section, we will highlight the targeted therapies that are currently approved or in development for NSCLC.

\section{Targeted therapies for NSCLC}

Identification of gene mutations, amplifications, and rearrangements in NSCLC provides a pool of new targets to be used in drug development. Targeted therapies include small molecular inhibitors and monoclonal antibodies that bind and inhibit the molecular pathways that promote NSCLC progression. Introduction of targeted therapies to the clinic resulted in decreased toxicity and increased rate of disease-free survival for patients with NSCLC compared to those treated with standard chemotherapy [15-18]. Unfortunately, only a small percentage of patients with NSCLC are eligible for approved targeted therapies. Patients eligible for FDA approved targeted therapies (erlotinib, afatinib, crizotinib, and ceritinib) are those diagnosed with advanced stage lung adenocarcinomas with activating mutations in the EGFR gene or EML4-ALK fusions [2, 13, 19-22]. Lung squamous cell carcinomas and adenocarcinomas have differing genetic profiles and molecular drivers and therefore do not respond to the tyrosine kinase inhibitors approved for treatment of NSCLC [23]. 
Table 1 Lung adenocarcinoma and squamous cell carcinoma mutations, incidence, downstream effects, and targeted therapies

\begin{tabular}{|c|c|c|c|c|}
\hline $\begin{array}{l}\text { Genetic } \\
\text { alterations }\end{array}$ & $\begin{array}{l}\text { Incidence } \\
(\%)\end{array}$ & Downstream effect & Targeted therapy $^{a}$ & Sources \\
\hline \multicolumn{5}{|l|}{ Adenocarcinomas } \\
\hline EGFR (mut) & $\sim 15$ & $\begin{array}{l}\uparrow \text { Proliferation, survival, angiogenesis, } \\
\text { and metastasis }\end{array}$ & $\begin{array}{l}\text { Gefitinib, erlotinib, afatinib, AZD9291, } \\
\text { AZD8931 }\end{array}$ & {$[10,11]$} \\
\hline EML4-ALK (fus) & $2-7$ & $\uparrow$ Proliferation, survival, and migration & Crizotinib, ceritinib, alectinib & {$[11,79,80]$} \\
\hline KRAS (mut) & $\sim 30$ & $\begin{array}{l}\uparrow \text { Chemoresistance, proliferation, and } \\
\text { survival }\end{array}$ & N/A & {$[10]$} \\
\hline MET (amp) & $3-5$ & $\uparrow$ Cell survival, proliferation, and metastasis & $\begin{array}{l}\text { Tivantinib, crizotinib cabozantinib, ornatu- } \\
\text { zumab }\end{array}$ & {$[11,13,24,81]$} \\
\hline ROS1 (fus) & $1-2$ & $\uparrow$ Survival & Foretinib \& crizotinib & {$[13,24]$} \\
\hline RET (fus) & $1-2$ & $\uparrow$ Proliferation & Carbozantinib, vandetanib, ponatinib & [11] \\
\hline BRAF (mut) & $5-10$ & $\begin{array}{l}\text { 个 Resistance to EGFR inhibitors, proliferation, } \\
\text { and survival }\end{array}$ & Debrafenib, sorafenib & {$[10,24]$} \\
\hline TP53 (mut) & 46 & $\uparrow$ Growth, $\downarrow$ apoptosis & N/A & {$[10,11]$} \\
\hline \multicolumn{5}{|c|}{ Squamous cell carcinomas } \\
\hline FGFR1 (amp) & $16-25$ & $\begin{array}{l}\uparrow \text { Proliferation, survival, and chemoresist- } \\
\text { ance; } \downarrow \text { patient prognosis }\end{array}$ & Nintendanib, ponatinib, AZD4547, dovitinib & {$[9,11,12,82]$} \\
\hline PIK3CA (mut) & $8-18$ & $\uparrow$ Proliferation and survival & $\begin{array}{l}\text { Buparlisib, PX-866, BYL719, GDC-0941 or } \\
\text { inhibitors for AKT: AZD5363, MK-2206 }\end{array}$ & {$[9,11,13,24,82]$} \\
\hline DDR2 (mut) & 4 & $\begin{array}{l}\uparrow \text { Cell migration, invasion, proliferation, and } \\
\text { survival }\end{array}$ & Dasatinib & {$[9,13]$} \\
\hline MET (amp) & 3 & $\uparrow$ Cell survival, proliferation, and metastasis & $\begin{array}{l}\text { Tivantinib, crizotinib cabozantinib, onartu- } \\
\text { zumab }\end{array}$ & {$[12,24,81]$} \\
\hline SOX2 & 21 & $\uparrow$ Proliferation & N/A & [9] \\
\hline PTEN (mut \& del) & $15-29$ & 个PI3K signaling, proliferation, and survival & $\begin{array}{l}\text { PI3K inhibitors: buparlisib, PX-866, BYL719, } \\
\text { GDC-0941 or inhibitors for AKT: AZD5363, } \\
\text { MK-2206 }\end{array}$ & {$[9,11,24,82]$} \\
\hline TP53 (mut) & 81 & $\uparrow$ Growth, $\downarrow$ apoptosis & N/A & {$[9,11,12]$} \\
\hline CDKN2A (del) & 51 & $\uparrow$ Growth & N/A & [9] \\
\hline
\end{tabular}

N/A not available, currently not able to target efficiently with drugs, Mut mutations, Del deletions, Amp amplifications, Fus fusions

${ }^{\mathrm{a}}$ For detailed review of targeted drugs and clinical trials see $[2,11,13,24]$

Several reviews have been published this year on NSCLC targeted therapies; therefore this review contains a short description of targeted therapies approved or in development for NSCLC. For more information regarding targeted therapies in development and ongoing clinical trials see the following reviews $[2,11,13,24]$. Table 1 lists targeted therapies that are approved (bold font) or undergoing clinical trials for NSCLC and the effected pathways. Crizotinib is a tyrosine kinase inhibitor that inhibits ALK and other RTKs such as MET and ROS1 [25]. Crizotinib is currently approved for treatment of NSCLC that contain ALK rearrangements and is undergoing clinical trials for NSCLC with ROS1 rearrangements [26, 27]. Several compounds are undergoing clinical trials for targeted treatment of lung adenocarcinomas and lung squamous cell carcinomas with genetic alterations in MET, BRAF, ROS1, RET, FGFR1, and PIK3CA (Table 1). Examples of ongoing clinical trials can be seen in Table 2. Not all of the identified genetic abnormalities in NSCLC (KRAS, SOX2, CDKN2A, and TP53) are currently targetable by small molecule inhibitors or monoclonal antibodies [11, 13, 28]. However, therapies that target downstream signaling pathways for KRAS such as MEK (mitogen-activated protein kinase kinase 1) inhibitors are being investigated [24].

One of the largest problems associated targeted therapies is primary or acquired resistance. Primary resistance to EGFR inhibitors have been found in patients that harbor KRAS or certain EGFR point mutations (T790) [29-31]. However, mutations of KRAS and EGFR are mutually exclusive [10]. Expression of Bim after treatment with tyrosine kinase inhibitors is also associated with primary resistance. Patients who have low expression of the pro-apoptotic protein Bim or have polymorphisms altering the function of Bim have lower response to EGFR and ALK inhibitors [31]. Use of tyrosine kinase inhibitors gefitinib, erlotinib, and crizotinib for NSCLC treatment invariably leads to acquired drug resistance 


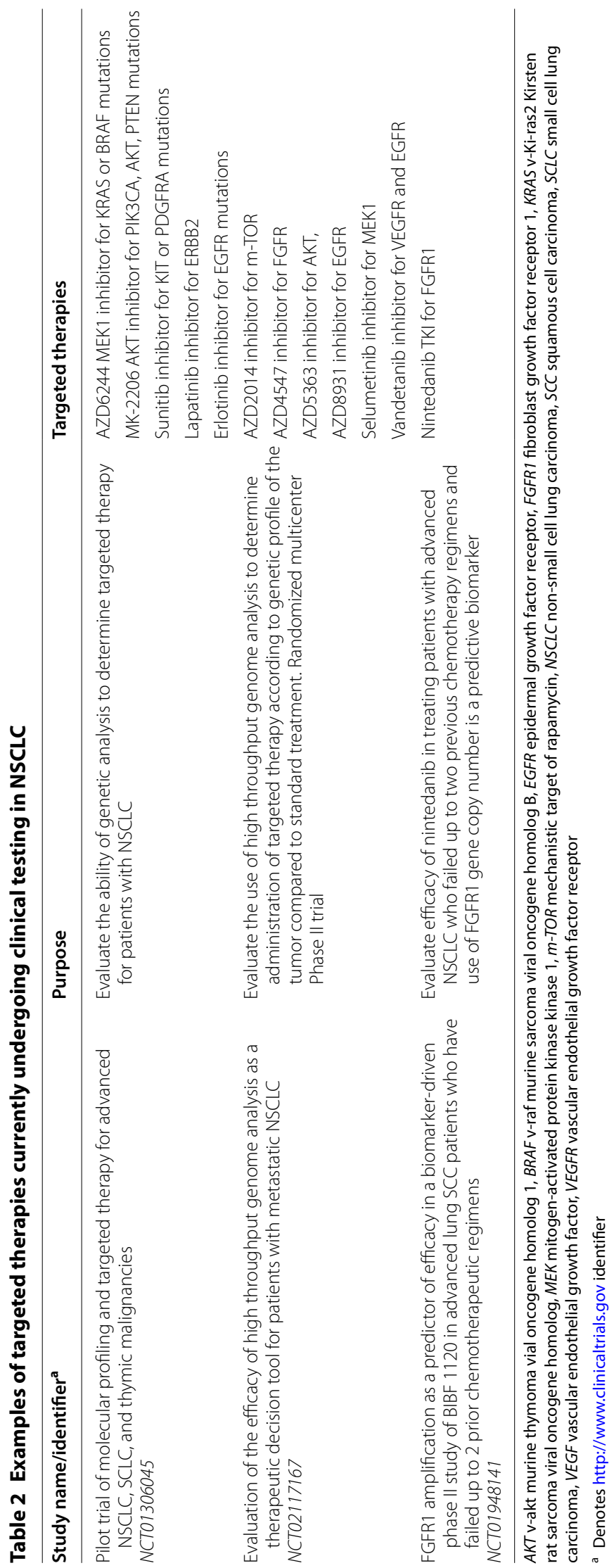


$[32,33]$. Mutations in the EGFR gene (T790M) or alterations in MET(amplification), BRAF(mutation), HER2 (amplification), PIK3CA (mutation), or PTEN (loss) leads to gefitinib and erlotinib resistance [33]. Resistance to ALK inhibitors occurs due to mutations in ALK (L1196M), amplifications of ALK, or activation of EGFR or KRAS that bypass the inhibition induced by tyrosine kinase inhibitor crizotinib [19, 34, 35]. Second generation inhibitors afatinib and ceritinib are approved for use in the FDA and have shown some promise in patients who were previously treated with first generation tyrosine kinase inhibitors for EGFR or ALK (respectively) [19, 34, 36]. In a phase IIb/III trial, afatinib increased progression free survival (3.3 months) of patients with advanced NSCLC that progressed after treatment with erlotinib, gefitinib, or both compared to placebo group (1.1 months $\mathrm{P}<0.0001)$ [36]. In a phase I trial, ceritinib in 114 patients with advanced NSCLC had an overall response rate of $58 \%[19,34]$. Response rate for ceritinib in patients who had disease progression after use of crizotinib was $56 \%$. Genetic analysis of 19 tumors from patients that previously had crizotinib therapy, showed patients responded to ceritinib even if they had the presence of ALK resistance mutation (L1196M) [19, 34].

Targeted therapeutics is a growing field in which there is a great need for therapies (1) that can be used for squamous cell carcinoma patients and (2) that overcome resistance associated with the available targeted therapies. Targeted therapies give the clinician the ability to select NSCLC treatments based on the molecular characteristics of the patients' cancer. Personalized therapy addresses the fact that cancers are a heterogeneous disease in which no two tumors are identical. The generalized therapeutic approach commonly used does not take into account molecular mechanisms that lead to chemoresistance and recurrence [37]. Clinical validation is needed to determine if genetic analysis based selection of targeted therapies can increase patient survival. Several clinical studies are evaluating the use of genetic analysis to determine a personalized treatment plan for NSCLC patients using several different arms of targeted treatments. Two examples of ongoing clinical trials can be found in Table 2 in which researchers are using therapies that target pathways modulated in NSCLC. Choosing the optimal treatment is a difficult process, but the implementation of biomarkers can provide clinicians with information that can be used in selection of NSCLC treatment.

\section{Biomarkers and NSCLC}

Seventy-nine percent of patients diagnosed with lung cancer present with regional or distant metastases [1]. The 5 years survival rate for patients diagnosed with early stage lung cancer is 27 and $50 \%$ greater than patients diagnosed with regional or distant metastases, respectively [1]. The National Lung Screening Trial found that early detection of lung cancer using low-dose computed tomography $(\mathrm{CT})$ resulted in a $20 \%$ reduction in mortality [38]. However, CT scans are unable to differentiate between benign and malignant lesions. Follow-up lung biopsies found that $96.4 \%$ of the lesions found by CT were benign [38]. The high percentage of false positive results, costs of CT scans, and stress to patients suggests CT scans are not practical for early lung cancer screening. Although early diagnosis gives an advantage toward patient survival, $36 \%$ of patients with stage I to II NSCLC recur 5 years after surgery [39]. Gene mutations and protein expression can impact patient survival. For example, patients with deletions in exon 19 and mutations in exon 21 had a longer overall survival after treatment with gefitinib or erlotinib [7, 40]. High expression of ERCC1 (excision repair cross-complementation group 1) mRNA or protein is associated with decreased overall survival in NSCLC patients treated with platinum based therapies $[41,42]$.

Investigation of genetic alterations has enabled the identification of key molecular changes that occur during the pathogenesis of lung cancer that can be used as biomarkers for detecting and treating lung cancer. Biomarkers are detectable changes in DNA, RNA, protein, lipids, etc., that can be used for (1) detecting and diagnosing lung cancer, (2) determining prognosis, (3) predicting patient response to therapy, and 4) choosing an optimal treatment regimen for NSCLC patients [43-45]. Utilization of biomarkers will allow clinical oncologists to select a personalized treatment option that will give the patient the greatest chance of survival, decrease toxicity, and unnecessary procedures [44, 45]. Investigative studies for lung cancer biomarkers have been conducted using cancer tissue, blood, lung condensate, sputum, and saliva samples [46-51]. In the following sections, we will explore the clinical potential and benefits of using gene biomarkers in the clinic to detect and treat NSCLC.

\section{Gene biomarkers: implications for early detection and diagnosis of NSCLC}

Biomarkers extracted from biofluids (blood, sputum, and saliva) are under investigation for the diagnosis of lung cancer without the use of invasive procedures required to collect lung cancer or bronchial epithelial cells [52, 53]. Blood samples extracted from NSCLC patients contain circulating cell free DNA (cfDNA; normal and tumor DNA), RNA, and mononuclear and tumor cells all of which are sources of genetic material that can be used for identification of biomarkers to detect lung cancer $[52,54,55]$. A multi-marker panel consisting of the 
circulating expression of cfDNA, mRNA expression of peptidylarginine deaminase type 4 (PADA) and proplatelet basic protein (PPBP) was able to discriminate between patients with NSCLC and controls with a sensitivity of $92 \%$ and a specificity of $89 \%$ [56]. Increased expression of cfDNA can be detected in the peripheral blood of NSCLC patients as early as stage IA compared to controls demonstrating the potential of cfDNA to be used in early detection of lung cancer [57]. Although cfDNA can be detected as early as stage I, it is associated with a lower sensitivity. Using a new strategy to analyze circulating tumor cells known as cancer personalized profiling by deep sequencing (CAPP-Seq), Newman et al. were able to detect circulating tumor DNA in $100 \%$ of NSCLC between the stages of II-IV and $50 \%$ of stage I tumors with specificity of $96 \%$ for both groups [58]. Studies in peripheral blood mononuclear cells have examined gene expression profiles in order to identify biomarkers that can be used for diagnosis of breast, urinary bladder, and lung cancers [54, 59, 60]. Showe et al. [54] identified a 29 mRNA signature from peripheral mononuclear cells of patients with NSCLC that distinguished with $91 \%$ sensitivity and $80 \%$ specificity patients with cancer from controls. Clinical trials are vital to validate biomarkers before use in the clinic. Search of http://www.clinicaltrials.gov yielded only one clinical trial based on our search parameters that is looking for gene biomarkers in the blood that can be used for diagnosis of NSCLC (http://www.clinicaltrials.gov identifier NCT02169349; Table 3).

Gene expression analyses of saliva and sputum samples have identified possible biomarkers that have clinical potential in detecting NSCLC. In 2012 Zhang et al. [46] identified and pre-validated seven mRNA transcripts [BRAF (v-raf murine sarcoma viral oncogene homolog B1), CCNI (cyclin I) EGFR, FGF19 (fibroblast growth factor 19), FRS2 (fibroblast growth factor receptor substrate 2), GREB1 (growth regulation by estrogen in breast cancer 1), and LZTS1 (leucine zipper, putative tumor suppressor 1)] expressed in the saliva from patients with NSCLC. A multi-marker panel measuring mRNA expression of CCN1, EGFR, FGF19, FRS2, and GREB1 in saliva, differentiated patients with lung cancer from controls with a sensitivity of $93.75 \%$ and specificity of $82.8 \%$ [46]. Currently, a clinical validation study evaluating the detection of lung cancer using a single or multi-marker panel of the seven mRNA transcripts identified by Zhang et al. [46] is recruiting patients with lung lesions suspected of having lung cancer (NCT02294578; Table 3).

Gene alterations have been identified from sputum samples collected from NSCLC patients suggesting sputum can be used to identify genetic abnormalities in lung cancer [51, 61, 62]. Gene analysis performed on the sputum of 49 NSCLC patients, 49 patients with COPD, and
49 healthy smokers, identified 15 genes with significant differences in copy number in patients with NSCLC compared to controls. A multi-marker panel containing 6 of the identified altered genes (ENO1, FHIT, HYAL2, SKP2, CDKN2A, and 14-3-3zeta) were able to differentiate between patients with NSCLC and control with $86.7 \%$ specificity and $93.9 \%$ sensitivity [63]. Further studies are needed to validate biomarkers in the sputum prior to use in the clinic. The ability to detect the presence of NSCLC from fluid samples can aid in decreasing the cost and stress to patients associated with current methods (biopsies and CT scans) used to differentiate between a benign and malignant small nodule that detected using CT scans. However, more sensitive methods are needed to detect the presence of stage I lung cancer.

\section{Gene biomarkers: implications for use as NSCLC predictive and prognostic biomarkers}

Several studies have examined the genetic profiles of NSCLC to identify prognostic and predictive gene biomarkers. A prognostic biomarker is a measureable factor that can be used to ascertain the likelihood of an event such as; recurrence, drug resistance, or metastasis to occur irrespective of treatment [64]. Whereas predictive biomarkers provide information concerning the benefits of a treatment for the patient such as increased survival or tumor response [64]. Prognostic and predictive biomarkers can be used to tailor chemotherapy treatments based on gene mutations or expression resulting in increased patient survival. Several studies have investigated the efficacy of selecting chemotherapies based on expression of genes ERCC1 (excision repair cross complementing gene 1), RRM1 (ribonucleotide reductase), TS (thymidylate synthase), TUBB3 (type III $\beta$-tubulin), and BRCA1 (breast cancer susceptibility gene 1) that are associated with chemoresistance in NSCLC [42, 47, $48,65]$. Miao et al. [48] conducted a retrospective analysis and found that chemotherapy selection based on gene expression of ERCC1 (platinum based therapies resistance), RRM1 (gemcitabine resistance), TS (pemetrexed resistance), and TUBB3 (vincristine resistance) in tumors resulted in higher rate of disease free survival $[1$ year $=66.7$ vs. $44.7 \%(\mathrm{P}=0.014) ; 2$ year 48.9 vs. $27.2 \%(\mathrm{P}=0.010)$ ] in stage IIIA NSCLC patients [48]. Furthermore, Zhang et al. [65] found that patients given a tailored chemotherapy regimen based on presence of ERCC1, RRM1, and TUBB3 had higher 1 year survival rates $(69.5 \%)$ and longer progression free survival time (5.2 months) compared to patients given standard treatment of gemcitabine plus cisplatin [survival rate $=40.9 \%$ $(\mathrm{P}=0.021)$ and progression free survival time 4.1 months $(P=0.0260)]$. The results from these studies suggest personalized therapy selection based on expression of genes 


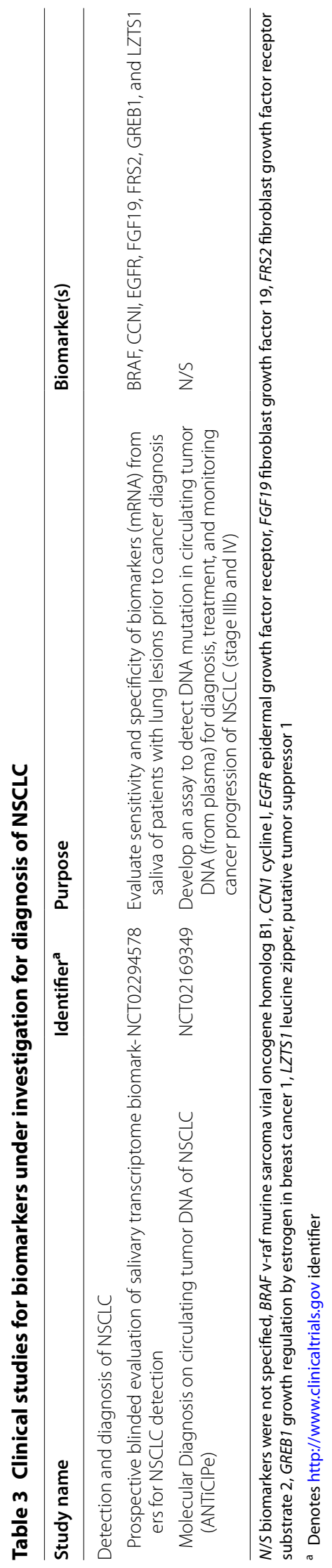


associated with chemoresistance can be used to increase patient response. However, these studies did not find a statistically significant change in overall survival and more validation needs to be done before implementation in the clinic. Clinical validation studies NCT01424709, NCT00792701, and NCT02145078 are investigating the effect of selecting chemotherapy for NSCLC patients using expression of ERCC1, TS, RRM1, and BRCA1, mRNA in different combinations, on patient response and survival (Table 4).

The implementation of targeted therapies has resulted in a need for predictive biomarkers to determine patient population that would benefit from their use. EGFR mutations and ALK rearrangements are examples of predictive biomarkers that are tested prior to use of gefitinib, erlotinib, afatinib, crizotinib, and ceritinib $[7,66,67]$. In 2013, the College of American Pathologists, International Association for the Study of Lung Cancer, and Association for molecular Pathology established guidelines for the molecular testing of all advanced stage lung adenocarcinomas for EGFR mutations and ALK rearrangements prior to treatment [68]. Several clinical trials are being conducted to test the efficacy of new targeted therapies in conjunction with evaluating predictive biomarkers for the treatment of NSCLC. An example of this can be found in Table 2 in which the gene copy number of FGFR1 is being tested to predict patient response to the tyrosine kinase inhibitor nintedanib undergoing clinical evaluation for treatment of NSCLC with FGFR1 amplifications (Table 2).

Molecular profiling of NSCLC is generally performed on biopsies that contain a small amount of tumor and stromal cells and are extracted by using invasive bronchoscopy or transthoracic needle biopsy. Therefore biomarker analysis using tumor tissue for selection of treatment for patients must be highly sensitive, selective, cost effective, reproducible, and have a quick turn-around time [4, 44, 69]. Furthermore, different areas of a tumor and metastatic sites can have dissimilar genetic profiles making it difficult to identify and extract biomarkers to monitor disease progression and response to therapy [4, 44, 69]. Peripheral blood samples containing circulating tumor cells (CTC) and free circulating tumor DNA (ctDNA) may provide a source to measure biomarkers prior to treatment. EGFR activating mutations associated with response to TKIs have been identified in DNA extracted from CTCs and in free ctDNA [70-73]. EGFR mutations analyzed from peripheral blood samples correlated with DNA analysis from matched tumor tissue; however ctDNA had a greater sensitivity for detecting EGFR mutations than DNA extracted from CTCs [70, 72, 73]. An analysis conducted by Yung et al. [73] was able to identify patients with EGFR mutations using ctDNA from plasma with an $92 \%$ sensitivity and $100 \%$ specificity compared to analysis using DNA extracted from NSCLC patients. Mutations in KRAS and ALK rearrangements have also been found in analyses on CTCs or ctDNA and correlate with mutation analysis in match tumor samples $[74,75]$. A list representing ongoing clinical trials investigating the use of biomarkers as predictive and prognostic factors from tumors and peripheral blood, can be found in Table 4 .

Biomarkers extracted from blood, saliva, and sputum have the possible advantage of providing early diagnosis of lung cancer and information that can be used for treatment selection without the use of invasive procedures. Multiple specimens can also be analyzed allowing the capabilities to monitor disease progression and response to therapy. This review highlighted several biomarker studies for use detecting and treating NSCLC. However, validation studies and standardization of biomarker analysis are needed before biomarkers are employed in the clinic [76].

\section{Conclusions}

Analysis of gene alterations has provided invaluable insight that has spurred the development of targeted therapies for NSCLC. The benefits of understanding the molecular changes promoting lung carcinogenesis go beyond drug development. Identification and validation of biomarkers that can be used to provide early detection and aid in the selection of personalized therapy are currently undergoing clinical testing. Biomarkers for early detection of lung cancer have the potential to be combined with current $\mathrm{CT}$ scans or alone to identify the presence of cancers without requiring invasive procedures. Utilization of biomarkers in the clinic for determination of patients' prognosis and response to therapy are invaluable tools that may increase patient survival and decrease toxicity due to ineffective treatments. However, understanding the genetic changes in NSCLC is just one side of the coin. Transcriptomic and proteomic studies not covered in this review are vital in understanding the downstream effect of gene mutations; and in identifying other mechanisms that promote cancer progression. DNA methylation, miRNA, and protein expression are all possible types of biomarkers that can be used for early detection, determining prognosis, and predicting patient response to therapy in NSCLC $[43,77,78]$. 


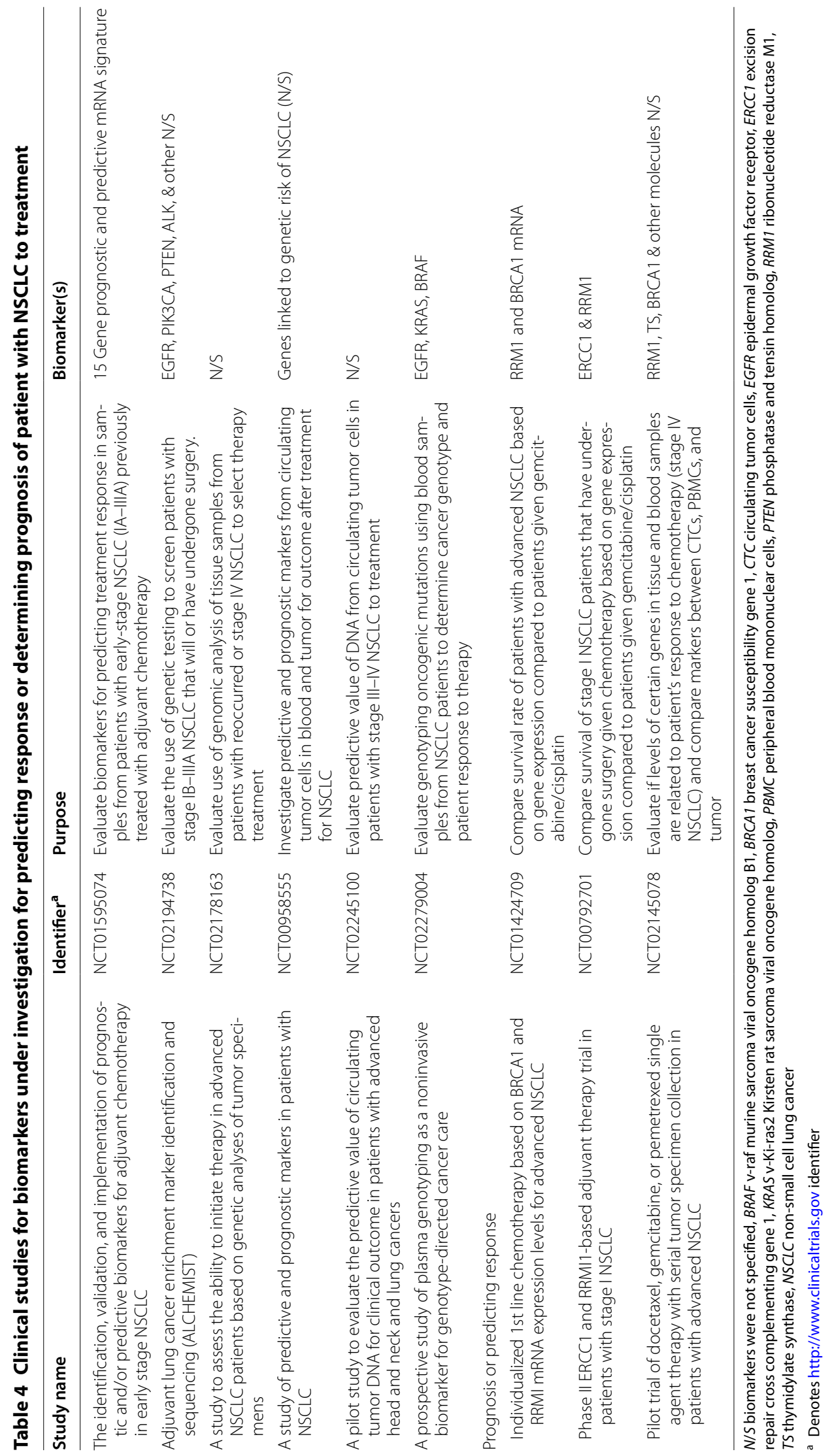




\section{Abbreviations}

AKT: v-akt murine thymoma vial oncogene homolog 1; ALK: Anaplastic lymphoma kinase; BRAF: v-raf murine sarcoma viral oncogene homolog $B ; C T$ : Computed tomography; CDNA: Circulating DNA; ctDNA: Circulating tumor DNA; CTC: Circulating tumor cells; EGFR: Epidermal growth factor receptor; EML4-ALK: Echinoderm microtubule associated protein like 4 and anaplastic lymphoma kinase fusion; FGFR1: Fibroblast growth factor receptor 1; KRAS: v-Ki-ras2 Kirsten rat sarcoma viral oncogene homolog; NSCLC: Non-small cell lung cancer; SCLC: Small-cell lung cancer.

\section{Authors' contributions}

MC designed manuscript, analyzed literature, wrote drafts of manuscript, and created tables. PPC oversaw manuscript progression, aided in design of manuscript, and made significant edits, and revisions of manuscript. All authors read and approved the final manuscript.

\section{Author details}

${ }^{1}$ Lineberger Comprehensive Cancer Center, University of North Carolina at Chapel Hill, Chapel Hill, NC 27599, USA. ${ }^{2}$ Department of Radiation Oncology, The University of Mississippi Medical Center Cancer Institute, 350 W Woodrow Wilson Ave, Jackson, MS 39213, USA. ${ }^{3}$ Department of Biomedical Sciences, University of Mississippi, National Center for Natural Products Research, Oxford, MS, USA.

\section{Competing interests}

The authors declare that they have no competing interests.

Received: 22 June 2015 Accepted: 15 October 2015

Published online: 24 November 2015

\section{References}

1. Siegel RL, Miller KD, Jemal A (2015) Cancer statistics. CA Cancer J Clin 65(1):5-29. doi:10.3322/caac.21254

2. Wood SL, Pernemalm M, Crosbie PA, Whetton AD (2015) Molecular histology of lung cancer: from targets to treatments. Cancer Treat Rev 41(4):361-375. doi:10.1016/j.ctrv.2015.02.008

3. Coco S, Truini A, Vanni I, Dal Bello MG, Alama A, Rijavec E et al (2015) Next generation sequencing in non-small cell lung cancer: new avenues toward the personalized medicine. Curr Drug Targets 16(1):47-59

4. Li T, Kung HJ, Mack PC, Gandara DR (2013) Genotyping and genomic profiling of non-small-cell lung cancer: implications for current and future therapies. J Clin Oncol 31(8):1039-1049. doi:10.1200/JCO.2012.45.3753

5. Hirsch FR, Varella-Garcia M, Bunn PA Jr, Franklin WA, Dziadziuszko R, Thatcher $\mathrm{N}$ et al (2006) Molecular predictors of outcome with gefitinib in a phase III placebo-controlled study in advanced non-small-cell lung cancer. J Clin Oncol 24(31):5034-5042. doi:10.1200/JCO.2006.06.3958

6. Lynch TJ, Bell DW, Sordella R, Gurubhagavatula S, Okimoto RA, Brannigan BW et al (2004) Activating mutations in the epidermal growth factor receptor underlying responsiveness of non-small-cell lung cancer to gefitinib. New Engl J Med 350(21):2129-2139. doi:10.1056/NEJMoa040938

7. Jackman DM, Yeap BY, Sequist LV, Lindeman N, Holmes AJ, Joshi VA et al (2006) Exon 19 deletion mutations of epidermal growth factor receptor are associated with prolonged survival in non-small cell lung cancer patients treated with gefitinib or erlotinib. Clin Cancer Res 12(13):39083914. doi:10.1158/1078-0432.CCR-06-0462

8. da Cunha Santos g, Shepherd FA, Tsao MS (2011) EGFR mutations and lung cancer. Annu Rev Pathol 6:49-69. doi:10.1146/ annurev-pathol-011110-130206

9. Cancer Genome Atlas Research N (2012) Comprehensive genomic characterization of squamous cell lung cancers. Nature 489(7417):519-525. doi:10.1038/nature11404

10. Cancer Genome Atlas Research N (2014) Comprehensive molecular profiling of lung adenocarcinoma. Nature 511 (7511):543-550. doi:10.1038/ nature13385

11. Richer AL, Friel JM, Carson VM, Inge LJ, Whitsett TG (2015) Genomic profiling toward precision medicine in non-small cell lung cancer: getting beyond EGFR. Pharmacogn Personal Med 8:63-79. doi:10.2147/PGPM. S52845
12. Kim HS, Mitsudomi T, Soo RA, Cho BC (2013) Personalized therapy on the horizon for squamous cell carcinoma of the lung. Lung Cancer 80(3):249-255. doi:10.1016/j.lungcan.2013.02.015

13. Chan BA, Hughes BG (2015) Targeted therapy for non-small cell lung cancer: current standards and the promise of the future. Transl Lung Cancer Res 4(1):36-54. doi:10.3978/j.issn.2218-6751.2014.05.01

14. Stratton MR, Campbell PJ, Futreal PA (2009) The cancer genome. Nature 458(7239):719-724. doi:10.1038/nature07943

15. Maemondo M, Inoue A, Kobayashi K, Sugawara S, Oizumi S, Isobe H et al (2010) Gefitinib or chemotherapy for non-small-cell lung cancer with mutated EGFR. N Engl J Med 362(25):2380-2388. doi:10.1056/ NEJMoa0909530

16. Shepherd FA, Rodrigues Pereira J, Ciuleanu T, Tan EH, Hirsh V, Thongprasert S et al (2005) Erlotinib in previously treated non-small-cell lung cancer. N Engl J Med 353(2):123-132. doi:10.1056/NEJMoa050753

17. Zhou C, Wu YL, Chen G, Feng J, Liu XQ, Wang C et al (2011) Erlotinib versus chemotherapy as first-line treatment for patients with advanced EGFR mutation-positive non-small-cell lung cancer (OPTIMAL, CTONG-0802): a multicentre, open-label, randomised, phase 3 study. Lancet Oncol 12(8):735-742. doi:10.1016/S1470-2045(11)70184-X

18. Solomon BJ, MokT, Kim DW, Wu YL, Nakagawa K, Mekhail T et al (2014) First-line crizotinib versus chemotherapy in ALK-positive lung cancer. N Engl J Med 371(23):2167-2177. doi:10.1056/NEJMoa1408440

19. Rothschild SI (2014) Ceritinib-a second-generation ALK inhibitor overcoming resistance in ALK-rearranged non-small cell lung cancer. Transl Lung Cancer Res 3(6):379-381. doi:10.3978/j.issn.2218-6751.2014.11.09

20. O'Bryant CL, Wenger SD, Kim M, Thompson LA (2013) Crizotinib: a new treatment option for ALK-positive non-small cell lung cancer. Ann Pharmacother 47(2):189-197. doi:10.1345/aph.1R002

21. Keating GM (2014) Afatinib: a review of its use in the treatment of advanced non-small cell lung cancer. Drugs 74(2):207-221. doi:10.1007/ s40265-013-0170-8

22. Cohen MH, Johnson JR, Chen YF, Sridhara R, Pazdur R (2005) FDA drug approval summary: erlotinib (Tarceva) tablets. Oncologist 10(7):461-466 doi:10.1634/theoncologist.10-7-461

23. Gold KA, Wistuba II, Kim ES (2012) New strategies in squamous cell carcinoma of the lung: identification of tumor drivers to personalize therapy. Clin Cancer Res 18(11):3002-3007. doi:10.1158/1078-0432. CCR-11-2055

24. Califano R, Abidin A, Tariq NU, Economopoulou P, Metro G, Mountzios G (2015) Beyond EGFR and ALK inhibition: unravelling and exploiting novel genetic alterations in advanced non small-cell lung cancer. Cancer Treat Rev 41(5):401-411. doi:10.1016/j.ctrv.2015.03.009

25. Ou SH (2011) Crizotinib: a novel and first-in-class multitargeted tyrosine kinase inhibitor for the treatment of anaplastic lymphoma kinase rearranged non-small cell lung cancer and beyond. Drug Des Dev Ther 5:471-485. doi:10.2147/DDDT.S19045

26. Kazandjian D, Blumenthal GM, Chen HY, He K, Patel M, Justice R et al (2014) FDA approval summary: crizotinib for the treatment of metastatic non-small cell lung cancer with anaplastic lymphoma kinase rearrangements. Oncologist 19(10):e5-e11. doi:10.1634/theoncologist.2014-0241

27. Shaw AT, Ou SH, Bang YJ, Camidge DR, Solomon BJ, Salgia R et al (2014) Crizotinib in ROS1-rearranged non-small-cell lung cancer. N Engl J Med 371(21):1963-1971. doi:10.1056/NEJMoa1406766

28. Alamgeer M, Ganju V, Watkins DN (2013) Novel therapeutic targets in non-small cell lung cancer. Curr Opin Pharmacol 13(3):394-401. doi:10.1016/j.coph.2013.03.010

29. Pao W, Wang TY, Riely GJ, Miller VA, Pan Q, Ladanyi M et al (2005) KRAS mutations and primary resistance of lung adenocarcinomas to gefitinib or erlotinib. PLoS Med 2(1):e17. doi:10.1371/journal.pmed.0020017

30. Stewart EL, Tan SZ, Liu G, Tsao MS (2015) Known and putative mechanisms of resistance to EGFR targeted therapies in NSCLC patients with EGFR mutations-a review. Transl Lung Cancer Res 4(1):67-81. doi:10.3978/j.issn.2218-6751.2014.11.06

31. Gainor JF, Shaw AT (2013) Emerging paradigms in the development of resistance to tyrosine kinase inhibitors in lung cancer. J Clin Oncol 31(31):3987-3996. doi:10.1200/JCO.2012.45.2029

32. Spaans JN, Goss GD (2014) Trials to overcome drug resistance to EGFR and ALK targeted therapies - past, present, and future. Front Oncol 4:233. doi:10.3389/fonc.2014.00233 
33. Spaans JN, Goss GD (2014) Drug resistance to molecular targeted therapy and its consequences for treatment decisions in non-small-cell lung cancer. Front Oncol 4:190. doi:10.3389/fonc.2014.00190

34. Shaw AT, Kim DW, Mehra R, Tan DS, Felip E, Chow LQ et al (2014) Ceritinib in ALK-rearranged non-small-cell lung cancer. N Engl J Med 370(13):1189-1197. doi:10.1056/NEJMoa1311107

35. Rolfo C, Passiglia F, Castiglia M, Raez LE, Germonpre P, Gil-Bazo I et al (2014) ALK and crizotinib: after the honeymoon... what else? Resistance mechanisms and new therapies to overcome it. Transl Lung Cancer Res 3(4):250-261. doi:10.3978/j.issn.2218-6751.2014.03.01

36. Miller VA, Hirsh V, Cadranel J, Chen YM, Park K, Kim SW et al (2012) Afatinib versus placebo for patients with advanced, metastatic non-small-cell lung cancer after failure of erlotinib, gefitinib, or both, and one or two lines of chemotherapy (LUX-Lung 1): a phase $2 \mathrm{~b} / 3$ randomised trial. Lancet Oncol 13(5):528-538. doi:10.1016/S1470-2045(12)70087-6

37. Cimino GD, Pan CX, Henderson PT (2013) Personalized medicine for targeted and platinum-based chemotherapy of lung and bladder cancer. Bioanalysis 5(3):369-391. doi:10.4155/bio.12.325

38. Aberle DR, Adams AM, Berg CD, Black WC, Clapp JD, National Lung Screening Trial Research T et al (2011) Reduced lung-cancer mortality with low-dose computed tomographic screening. N Engl J Med 365(5):395-409. doi:10.1056/NEJMoa1102873

39. Kelsey CR, Marks LB, Hollis D, Hubbs JL, Ready NE, D'Amico TA et al (2009) Local recurrence after surgery for early stage lung cancer: an 11-year experience with 975 patients. Cancer 115(22):5218-5227. doi:10.1002/ cncr.24625

40. Pao W, Miller V, Zakowski M, Doherty J, Politi K, Sarkaria I et al (2004) EGF receptor gene mutations are common in lung cancers from "never smokers" and are associated with sensitivity of tumors to gefitinib and erlotinib. Proc Natl Acad Sci USA 101(36):13306-13311. doi:10.1073/ pnas.0405220101

41. Su C, Zhou S, Zhang L, Ren S, Xu J, Zhang J et al (2011) ERCC1, RRM1 and BRCA1 mRNA expression levels and clinical outcome of advanced non-small cell lung cancer. Med Oncol 28(4):1411-1417. doi:10.1007/ s12032-010-9553-9

42. Carnio S, Novello S, Papotti M, Loiacono M, Scagliotti GV (2013) Prognostic and predictive biomarkers in early stage non-small cell lung cancer: tumor based approaches including gene signatures. Transl Lung Cancer Res 2(5):372-381. doi:10.3978/j.issn.2218-6751.2013.10.05

43. Kalia M (2015) Biomarkers for personalized oncology: recent advances and future challenges. Metabolism 64(3 Suppl 1):S16-S21. doi:10.1016/j. metabol.2014.10.027

44. de Gramont A, Watson S, Ellis LM, Rodon J, Tabernero J, de Gramont A et al (2015) Pragmatic issues in biomarker evaluation for targeted therapies in cancer. Nat Rev Clin Oncol 12(4):197-212. doi:10.1038/ nrclinonc.2014.202

45. Bhatt AN, Mathur R, Farooque A, Verma A, Dwarakanath BS (2010) Cancer biomarkers_current perspectives. Indian J Med Res 132:129-149

46. Zhang L, Xiao H, Zhou H, Santiago S, Lee JM, Garon EB et al (2012) Development of transcriptomic biomarker signature in human saliva to detect lung cancer. Cell Mol Life Sci 69(19):3341-3350. doi:10.1007/ s00018-012-1027-0

47. Leng XF, Chen MW, Xian L, Dai L, Ma GY, Li MH (2012) Combined analysis of mRNA expression of ERCC1, BAG-1, BRCA1, RRM1 and TUBB3 to predict prognosis in patients with non-small cell lung cancer who received adjuvant chemotherapy. J Exp Clin Cancer Res 31:25. doi:10.1186/1756-9966-31-25

48. Miao J, Zhang W, Hu X, Chen S, Hu B, Li H (2015) Clinical evaluation of postoperative chemotherapy based on genetic testing in patients with stage IIIA non-small cell lung cancer. Thorac Cancer

49. Carpagnano GE, Spanevello A, Carpagnano F, Palladino GP, Prato R, Martinelli D et al (2009) Prognostic value of exhaled microsatellite alterations at 3p in NSCLC patients. Lung Cancer 64(3):334-340. doi:10.1016/j. lungcan.2008.09.004

50. Zander T, Hofmann A, Staratschek-Jox A, Classen S, Debey-Pascher S, Maisel D et al (2011) Blood-based gene expression signatures in non-small cell lung cancer. Clin Cancer Res 17(10):3360-3367. doi:10.1158/10780432.CCR-10-0533

51. Li R, Todd NW, Qiu Q, Fan T, Zhao RY, Rodgers WH et al (2007) Genetic deletions in sputum as diagnostic markers for early detection of stage I non-small cell lung cancer. Clin Cancer Res 13(2 Pt 1):482-487. doi:10.1158/1078-0432.CCR-06-1593

52. Hassanein M, Callison JC, Callaway-Lane C, Aldrich MC, Grogan EL, Massion PP (2012) The state of molecular biomarkers for the early detection of lung cancer. Cancer Prev Res 5(8):992-1006. doi:10.1158/1940-6207. CAPR-11-0441

53. Minimo C, Bibbo M, Claudio PP, De Luca A, Giordano A (1999) The role of $\mathrm{pRb} 2 / \mathrm{p} 130$ protein in diagnosing lung carcinoma on fine needle aspiration biopsies. Pathol Res Pract 195(2):67-70. doi:10.1016/ S0344-0338(99)80072-7

54. Showe MK, Vachani A, Kossenkov AV, Yousef M, Nichols C, Nikonova EV et al (2009) Gene expression profiles in peripheral blood mononuclear cells can distinguish patients with non-small cell lung cancer from patients with nonmalignant lung disease. Cancer Res 69(24):9202-9210. doi:10.1158/0008-5472.CAN-09-1378

55. Bremnes RM, Sirera R, Camps C (2005) Circulating tumour-derived DNA and RNA markers in blood: a tool for early detection, diagnostics, and follow-up? Lung Cancer 49(1):1-12. doi:10.1016/j.lungcan.2004.12.008

56. Ulivi P, Mercatali L, Casoni GL, Scarpi E, Bucchi L, Silvestrini R et al (2013) Multiple marker detection in peripheral blood for NSCLC diagnosis. PLoS One 8(2):e57401. doi:10.1371/journal.pone.0057401

57. Sozzi G, Conte D, Mariani L, Lo Vullo S, Roz L, Lombardo C et al (2001) Analysis of circulating tumor DNA in plasma at diagnosis and during follow-up of lung cancer patients. Cancer Res 61(12):4675-4678

58. Newman AM, Bratman SV, To J, Wynne JF, Eclov NC, Modlin LA et al (2014) An ultrasensitive method for quantitating circulating tumor DNA with broad patient coverage. Nat Med 20(5):548-554. doi:10.1038/nm.3519

59. Osman I, Bajorin DF, Sun TT, Zhong H, Douglas D, Scattergood J et al (2006) Novel blood biomarkers of human urinary bladder cancer. Clin Cancer Res 12(11 Pt 1):3374-3380. doi:10.1158/1078-0432.CCR-05-2081

60. Sharma P, Sahni NS, Tibshirani R, Skaane P, Urdal P, Berghagen H et al (2005) Early detection of breast cancer based on gene-expression patterns in peripheral blood cells. Breast Cancer Res 7(5):R634-R644. doi:10.1186/bcr1203

61. Chen JT, Ho WL, Cheng YW, Lee H (2000) Detection of p53 mutations in sputum smears precedes diagnosis of non-small cell lung carcinoma. Anticancer Res 20(4):2687-2690

62. Destro A, Bianchi P, Alloisio M, Laghi L, Di Gioia S, Malesci A et al (2004) K-ras and p16(INK4A)alterations in sputum of NSCLC patients and in heavy asymptomatic chronic smokers. Lung Cancer 44(1):23-32. doi:10.1016/j.lungcan.2003.10.002

63. Jiang F, Todd NW, Li R, Zhang H, Fang H, Stass SA (2010) A panel of sputum-based genomic marker for early detection of lung cancer. Cancer Prev Res 3(12):1571-1578. doi:10.1158/1940-6207.CAPR-10-0128

64. Italiano A (2011) Prognostic or predictive? It's time to get back to definitions! J Clin Oncol 29(35):4718. doi:10.1200/JCO.2011.38.3729 (author reply-9)

65. Zhang Q, Zhu X, Zhang L, Sun S, Huang J, Lin Y (2014) A prospective study of biomarker-guided chemotherapy in patients with non-small cell lung cancer. Cancer Chemother Pharmacol 74(4):839-846. doi:10.1007/ s00280-014-2513-x

66. Zhang NN, Liu YT, Ma L, Wang L, Hao XZ, Yuan Z et al (2014) The molecular detection and clinical significance of ALK rearrangement in selected advanced non-small cell lung cancer: ALK expression provides insights into ALK targeted therapy. PLoS One 9(1):e84501. doi:10.1371/journal. pone.0084501

67. Sequist LV, Bell DW, Lynch TJ, Haber DA (2007) Molecular predictors of response to epidermal growth factor receptor antagonists in non-small-cell lung cancer. J Clin Oncol 25(5):587-595. doi:10.1200/ JCO.2006.07.3585

68. Lindeman NI, Cagle PT, Beasley MB, Chitale DA, Dacic S, Giaccone G et al (2013) Molecular testing guideline for selection of lung cancer patients for EGFR and ALK tyrosine kinase inhibitors: guideline from the College of American Pathologists, International Association for the Study of Lung Cancer, and Association for Molecular Pathology. J Mol Diagn\ 15(4):415-453. doi:10.1016/j.jmoldx.2013.03.001

69. Bergot E, Levallet G, Campbell K, Dubois F, Lechapt E, Zalcman G (2013) Predictive biomarkers in patients with resected non-small cell lung cancer treated with perioperative chemotherapy. Eur Respir Rev 22(130):565-576. doi:10.1183/09059180.00007113 
70. Kimura H, Kasahara K, Kawaishi M, Kunitoh H, Tamura T, Holloway B et al (2006) Detection of epidermal growth factor receptor mutations in serum as a predictor of the response to gefitinib in patients with non-small-cell lung cancer. Clin Cancer Res 12(13):3915-3921. doi:10.1158/1078-0432. CCR-05-2324

71. Maheswaran S, Sequist LV, Nagrath S, Ulkus L, Brannigan B, Collura CV et al (2008) Detection of mutations in EGFR in circulating lung-cancer cells. N Engl J Med 359(4):366-377. doi:10.1056/NEJMoa0800668

72. Punnoose EA, Atwal S, Liu W, Raja R, Fine BM, Hughes BG et al (2012) Evaluation of circulating tumor cells and circulating tumor DNA in non-small cell lung cancer: association with clinical endpoints in a phase Il clinical trial of pertuzumab and erlotinib. Clin Cancer Res 18(8):23912401. doi:10.1158/1078-0432.CCR-11-3148

73. Yung TK, Chan KC, Mok TS, Tong J, To KF, Lo YM (2009) Single-molecule detection of epidermal growth factor receptor mutations in plasma by microfluidics digital PCR in non-small cell lung cancer patients. Clin Cancer Res 15(6):2076-2084. doi:10.1158/1078-0432.CCR-08-2622

74. Nie K, Jia Y, Zhang X (2015) Cell-free circulating tumor DNA in plasma/ serum of non-small cell lung cancer. Tumour Biol 36(1):7-19. doi:10.1007/ s13277-014-2758-3

75. Marchesi V (2013) Lung cancer: ALK status of NSCLC reflected in CTCs. Nat Rev Clin Oncol 10(7):366. doi:10.1038/nrclinonc.2013.89

76. Khleif SN, Doroshow JH, Hait WN (2010) Collaborative A-F-NCB. AACRFDA-NCI Cancer Biomarkers Collaborative consensus report: advancing the use of biomarkers in cancer drug development. Clin Cancer Res 16(13):3299-3318. doi:10.1158/1078-0432.CCR-10-0880

77. Lu F, Zhang HT (2011) DNA methylation and nonsmall cell lung cancer. Anat Rec 294(11):1787-1795. doi:10.1002/ar.21471

78. Del Vescovo V, Grasso M, Barbareschi M, Denti MA (2014) MicroRNAs as lung cancer biomarkers. World J Clin Oncol 5(4):604-620. doi:10.5306/ wjco.v5.14.604

79. Kwak EL, Bang YJ, Camidge DR, Shaw AT, Solomon B, Maki RG et al (2010) Anaplastic lymphoma kinase inhibition in non-small-cell lung cancer. N Engl J Med 363(18):1693-1703. doi:10.1056/NEJMoa1006448

80. Soda M, Choi YL, Enomoto M, Takada S, Yamashita Y, Ishikawa S et al (2007) Identification of the transforming EML4-ALK fusion gene in non-small-cell lung cancer. Nature 448(7153):561-566. doi:10.1038/ nature05945

81. Schildhaus HU, Schultheis AM, Ruschoff J, Binot E, Merkelbach-Bruse S, Fassunke J et al (2015) MET amplification status in therapy-naive adenoand squamous cell carcinomas of the lung. Clin Cancer Res 21(4):907915. doi:10.1158/1078-0432.CCR-14-0450

82. Paik PK, Johnson ML, D'Angelo SP, Sima CS, Ang D, Dogan S et al (2012) Driver mutations determine survival in smokers and never-smokers with stage IIIB/IV lung adenocarcinomas. Cancer 118(23):5840-5847. doi:10.1002/cncr.27637

\section{Submit your manuscript to a SpringerOpen ${ }^{\circ}$ journal and benefit from:}

- Convenient online submission

- Rigorous peer review

- Immediate publication on acceptance

- Open access: articles freely available online

- High visibility within the field

- Retaining the copyright to your article

Submit your next manuscript at $>$ springeropen.com 